\title{
Morphodifferentiation of Skeletal Muscle Fiber Ends at the Myotendinous Junction in the Postnatal Chinese Hamster: A Scanning Electron Microscopic Study
}

\author{
Yoji Nagano ${ }^{1}$, Yoshiro Matsuda ${ }^{1}$, Junzo Desaki ${ }^{2}$, Sadaaki OKI ${ }^{1}$, Kenji KitaOKa ${ }^{1}$, Hideo \\ OKUMURA $^{1}$ and Taihoh SHIBATA ${ }^{1}$ \\ Departments of Orthopedic Surgery ${ }^{1}$ and Anatomy ${ }^{2}$, Ehime University School of Medicine, Shigenobu, Ehime, Japan \\ Received December 8, 1997
}

\begin{abstract}
Summary. The postnatal morphodifferentiation of muscle fiber ends at the myotendinous junction was examined by scanning electron microscopy in gastrocnemius muscles of the Chinese hamster. Muscle fiber ends during the first week were simply conical or slightly complex, having a few pit-like invaginations and longitudinal and narrow clefts. By the second week, fiber ends gradually became complicated with an increased number of clefts and finger-like processes. Pits and short clefts linearly arranged towards the fiber tip were visible until the second week. This possibly indicates the linear elongation of the clefts by the fusion of adjacent pits to one another and to preexisting clefts. By the fourth week, the fiber ends had almost fully matured and displayed numerous cytoplasmic processes and lateral grooves.
\end{abstract}

Myotendinous junctions are sites that transmit forces generated by muscle contractions to the tendon collagen fibers. Many transmission electron microscope (TEM) studies of mammalian skeletal muscles have clarified the fine structural features of muscle fiber ends in great detail (GELBER et al., 1960; ISHIKAWA, 1965; MACKAY et al., 1969; HANAK and BOCK, 1971; MAIR and TOME, 1972; KORNELIUSSEN, 1973; TROT. TER et al., 1981, 1985b, 1987; Ovalle, 1987). Moreover, some recent scanning electron microscope (SEM) studies have demonstrated the actual surface topography of the muscle fiber ends after the removal of tendon connective tissue components by $\mathrm{HCl}$ hydrolysis (TROTTER et al., 1985a; DESAKI, 1992) and KOH-collagenase methods (ABOU SALEM et al., 1993). This is characterized by surface specializations depending on the qualitative and quantitative combination of finger-like processes and lateral, longitudinal grooves and/or clefts which provide an increased cellular surface to reduce the tension per unit surface area.

Some TEM studies on mammalian developing myotendinous junctions (MAIR and TOME, 1972; OvALLE, 1987) indicate that the initial manifestation of the morphological differentiation at muscle fiber ends is the occurrence of sarcolemmal indentations and small, brush-like projections. Despite these studies, the overall developmental sequence of muscle fiber ends has not been fully depicted threedimensionally at the fine structural level.

The present study demonstrates the process of the postnatal differentiation of muscle fiber ends at the myotendinous junction in gastrocnemius muscles of the Chinese hamster as examined by SEM.

\section{MATERIALS AND METHODS}

This study was performed on the gastrocnemius muscle of 1, 2, 4, and 12-week-old Chinese hamsters (Cricetulus griseus), using 4 to 5 animals for each stage. The following experiments were conducted in accordance with the Guide for Animal Experimentation at Ehime University School of Medicine.

The animals were anesthetized by intraperitoneal injection of $0.05 \mathrm{mg} / \mathrm{kg}$ of pentobarbital sodium (Nembutal), and the muscles were fixed in situ for about 5 min with $3 \%$ glutaraldehyde in $0.1 \mathrm{M}$ phosphate buffer at $\mathrm{pH}$ 7.3. After excision, the myotendinous portions were dissected out and were further fixed for about $2 \mathrm{~h}$. They were washed with several changes of buffer and postfixed with $2 \%$ unbuffered osmium tetroxide for $30 \mathrm{~min}$. The specimens underwent the $\mathrm{HCl}$-hydrolysis procedure (DESAKI and 
UEHARA, 1981) to remove connective tissues. After drying by the critical point method and sputtercoating with platinum, the specimens were examined under a Hitachi S-500A scanning electron microscope.

\section{RESULTS AND DISCUSSION}

Adult (12 weeks) Chinese hamster muscle fibers, 20$30 \mu \mathrm{m}$ in diameter, abruptly tapered and formed a fiber end, exhibiting surface specialization at the myotendinous junction. The fiber ends were characterized by a complex arrangement of a number of finger-like cytoplasmic processes and a great number of longitudinal clefts or grooves at the lateral side along the fiber tip (Fig. 1), like normal adult mice (TROTTER et al., 1985a; DESAKI, 1992) and rats (ABOU SALEM et al., 1993). The finger-like cytoplasmic processes were $0.2-0.3 \mu \mathrm{m}$ in diameter and $2.0-8.0 \mu \mathrm{m}$ in length. The processes extending toward the longitudinal axis of the muscle fiber end were separated by longitudinal grooves $0.1-1.0 \mu \mathrm{m}$ in width.

Until the 7th day after birth, muscle fiber ends were conical in shape, with a rather smooth surface having a few pit-like invaginations about $0.1 \mu \mathrm{m}$ in diameter and/or showing a slightly complicated appearance with several conical cytoplasmic projections and an increased number of slits or grooves on their lateral surface (Fig. 2). Clefts were $0.1-0.2 \mu \mathrm{m}$ wide and less than $2.0 \mu \mathrm{m}$ long. Most finger-like processes were $0.2-$ $0.5 \mu \mathrm{m}$ in diameter and less than $3.0 \mu \mathrm{m}$ in length. The muscle fibers were $7 \mu \mathrm{m}$ along the mean diameter. In muscle fibers (12 $\mu \mathrm{m}$ along the mean diameter) at the 14th postnatal day, a great number of round or oval pits, $0.1-0.2 \mu \mathrm{m}$ in diameter, and/or short grooves, $0.1-0.2 \mu \mathrm{m}$ wide and less than $1.0 \mu \mathrm{m}$ long, often appeared linearly arranged leading up to the fiber tip (Fig. 3). In addition to many long slits and finger-like processes along the lateral muscle surface, individual conical cytoplasmic projections on the lateral side of fiber ends contained numerous pits and some series of pits (Fig. 3 inset).

At the 28th postnatal day, the mean diameter of muscle fibers was about $15 \mu \mathrm{m}$. The finger-like processes and slits in the muscle fiber ends increased in both number and size. The fiber ends exhibited almost identical shapes of mature fiber ends (Fig. 4). Slits with a width of $0.1-0.2 \mu \mathrm{m}$ increased in length up to $5.0 \mu \mathrm{m}$.

When investigating surface specialization of mammalian skeletal muscle fiber ends, SEM provides three-dimensional images of their elaborate morphology. The present SEM study showed in the gastrocnemius muscle of the postnatal Chinese hamster that muscle fiber ends were mostly simple and conical forms with a few pits and short slits during the first week after birth, and then developed into complex surface structures with numerous cytoplasmic processes and lateral longitudinal clefts and/or grooves by the end of the first month. These findings seem to be similar to the morphodifferentiation taking place in subneural apparatuses at the rat neuromuscular junctions during the first postnatal month (DESAKI and UEHARA, 1987) Accordingly, junctional folds in developing neuromuscular junctions are rapidly transformed from pit-like invaginations to slit-like folds by the 15th postnatal day, possibly resulting from the fusion of adjacent pits. Moreover, DESAKI (1992) has demonstrated by SEM that pits and slits run in a serial fashion along the lateral surface of regenerating muscle fiber ends in the dystrophic $(d y)$ mouse, and suggested that linear elongation takes place as a result of the fusion of adjacent pits and preexisting slits. Thus we suggest that the pit-to-slit transformation and linear elongation may occur in normally developing muscle fiber ends to form lateral longitudinal clefts and/or gooves, and to follow the formation of cytoplasmic processes.

Moreover, the formation of surface specializations of the muscle fiber ends also suggests that the intracellular membrane system may play an important role in supplying the increased plasma membrane of the complex surface area. In fact, developmental studies by TEM demonstrated that developing muscle fiber ends contain a large amount of ribosomes, well-developed Golgi apparatuses, mitochondria, elements of rough and smooth endoplasmic

Fig. 2. Scanning electron micrograph of a fiber end in the 7-day-old Chinese hamster, showing a slightly complicated appearance. The slits or clefts increase in number and several conical cytoplasmic projections are seen along the lateral muscle surface toward the fiber tip. $\times 8,600$

Fig. 3. Scanning electron micrograph of a fiber end in the 14-day-old Chinese hamster. The lateral surface of the fiber end consists of numerous slits, grooves, and cytoplasmic processes. Note that a cluster of pits (arrow) are still visible. $\times 3,300$. Inset. The series of the pits (arrowheads) are linearly arranged up to the tip of the conical cytoplasmic projection. $\times 12,000$

Fig. 4. Lateral surface view of a fiber end in the 28-day-old Chinese hamster, exhibiting almost the same appearance as mature muscle fiber ends. $\times 2,700$ 


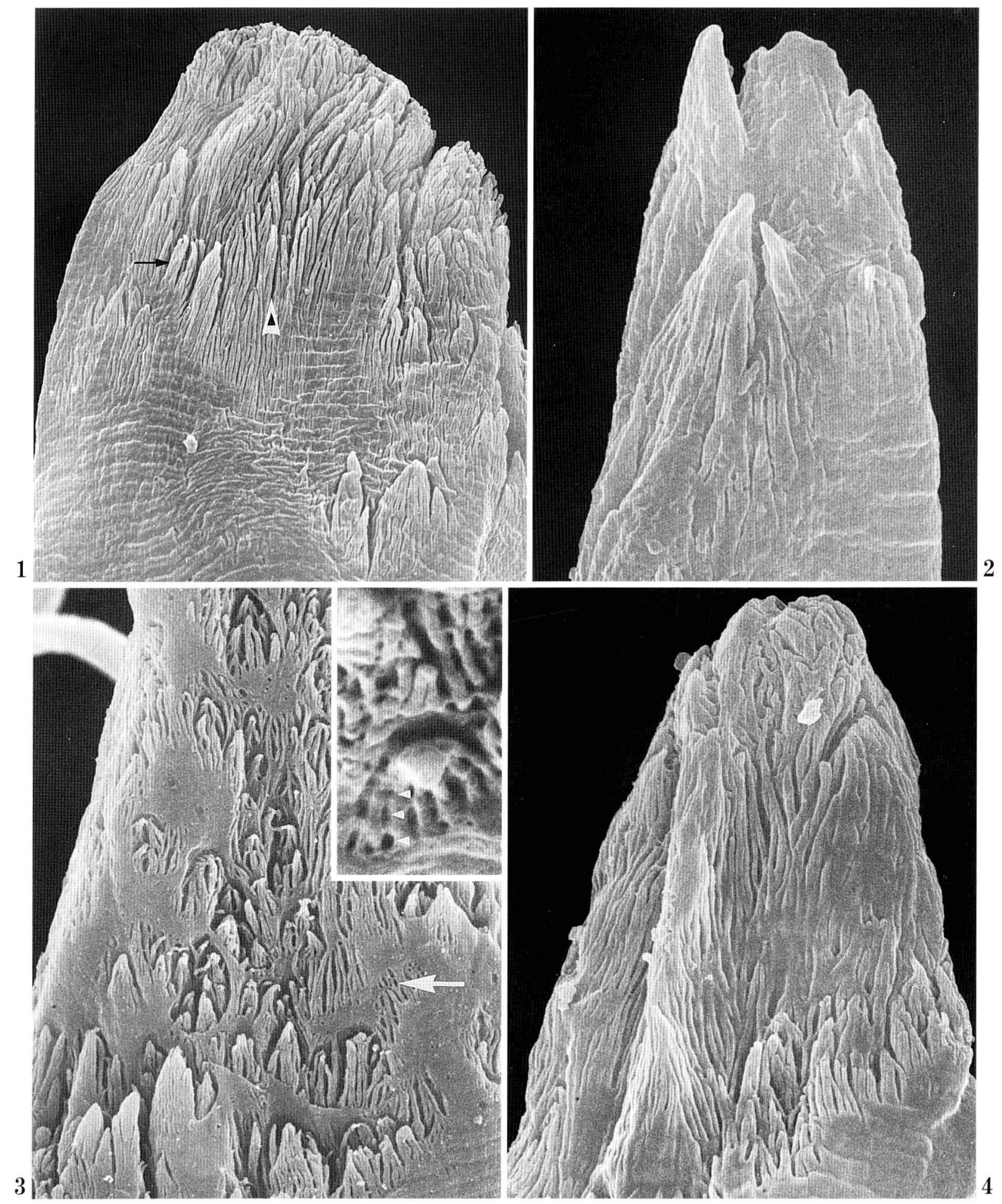

Fig. 1. Scanning electron micrograph of a mature (12 weeks) gastrocnemius muscle fiber end in the 12 -week-old Chinese hamster. Lateral surface of the fiber end shows a complicated appearance with numerous cytoplasmic processes (arrow) and longitudinal clefts or grooves (arrowhead). $\times 3,400$

Figs. 2-4. Legends on the opposite page. 
reticulum and cytoplasmic vesicles (MAIR and TOME, 1972; Ovalle, 1987). These TEM observations suggest that the ribosomes may actively synthesize contractile proteins, growing in length by the addition of sarcomere, and that the well-developed Golgi apparatuses may be involved in the increased secretion of intracellular vacuoles for the additional plasma membrane. It is of interest to note that, in developing neuromuscular junctions of the rat, vacuoles including basal lamina-like materials appear in the postsynaptic sarcoplasm during the first and second postnatal weeks, and that these vacuoles often attach to smooth-surfaced vesicles and/or coated vesicles and finally fuse with the plasma membrane to form junctional folds (DESAKI and UEHARA, 1987). These events may occur even in developing muscle fiber ends to supply the additional plasma membrane required for the formation of their highlyfolded surface structures. The morphogenesis of myotendinous junctions by TEM is in progress in our laboratory to clarify whether intracellular vacuoles are involved in supplying the plasma membrane for the structural differentiation of muscle fiber ends.

With respect to influences on the formation and maturation of complex surface specializations of the muscle fiber ends, moreover, it is tempting to speculate that neurotrophic factor(s) may play an important role. In fact, ZELENA (1976) has reported that axon terminals make contact with muscle fibers in myotendinous regions of developing rat muscles up to 5 days after birth, and thereafter axon terminals become detached from muscle fibers. From these observations, she suggests that the axon terminals, being obviously sensory in nature, may be involved in the differentiation of Golgi tendon organs. This nerve-myotendon relationship during postnatal development also suggests the possibility that these nerve terminals induce the formation of complex surface specializations of the muscle fiber ends. The functional significance of the temporary occurrence of the neuromuscular contacts in developing myotendinous regions remains for further studies.

\section{REFERENCES}

Abou Salem, E. A., K. Saito and H. Ishikawa: Scanning electron microscopy of tenotomized soleus muscles of the rat. Arch. Histol. Cytol. 56: 49-63 (1993).

DESAKI, J.: Scanning electron microscopical study of skeletal muscle fiber ends in normal and dystrophic mice. Arch. Histol. Cytol. 55: 449-452 (1992).
Desaki, J. and Y. Uehara: The overall morphology of neuromuscular junctions as revealed by scanning electron microscopy. J. Neurocytol. 10: 101-110 (1981).

: Formation and maturation of subneural apparatuses at neuromuscular junctions in postnatal rats: A scanning electron microscopical study. Devel. Biol. 119: 390-401 (1987).

Gelber, D., D. H. Moore and H. Ruska: Observation of the myotendon junction in mammalian skeletal muscle. Z. Zellforsch. 52: 396-400 (1960).

Hanak, H. and P. Bock: Die Feinstruktur der MuskelSehnenverbindung von Skelett- und Herzmuskel. J. Ultrastr. Res. 36: 68-85 (1971).

IsHIKAWA, H. : The fine structure of myotendon junction in some mammalian skeletal muscles. Arch. Histol. Jap. 25: 275-296 (1965).

KoRneliussen, H.: Ultrastructure of myotendinous junctions in Myxine and rat. Specializations between the plasma membrane and the lamina densa. Z. Anat. Entwickl.-Gesch. 142: 91-101 (1973).

Mackay, B., T. J. Harrop and A. R. Muir: The fine structure of muscle tendon junction in the rat. Acta Anat. 73: 588-604 (1969).

MaIR, W. P. G. and F. M. S. Tome: The ultrastructure of the adult and developing myotendinous junction. Acta Neuropathol. 21: 239-252 (1972).

Ovalle, W. K. : The human muscle-tendon junction. A morphological study during normal growth and at maturity. Anat. Embryol. 176: 281-294 (1987).

Trotter, J. A., K. Corbett and B. P. Avner: Structure and function of the murine muscle-tendon junction. Anat. Rec. 201: 293-302 (1981).

Trotter, J. A., A. Samora and J. M. Baca: Threedimensional structure of the murine muscle-tendon junction. Anat. Rec. 213: 16-25 (1985a).

Trotter, J. A., K. Hsi, A. Samora and C. Wolfsy: A morphometric analysis of the muscle-tendon junction. Anat. Rec. 213: 26-32 (1985b).

Trotter, J. A., K. Hsi, A. Samora and C. Wolfsy: Stereological analysis of the muscle-tendon junction in the aging mouse. Anat. Rec. 218: 288-293 (1987).

ZELENA, J.: Sensory terminals on extrafusal muscle fibers in myotendinous junction of developing rat muscle. J. Neurocytol. 5: 447-463 (1976).

Dr. Yoji NAGANO
Department of Orthopedic Surgery
Ehime University School of Medicine
Shigenobu, Ehime
791-0295 Japan
長 野 洋 司
$791-0295$
愛媛県温泉郡重信町志津川
愛媛大学医学部
整形外科学教室

